It is very important to gain access to communities through trusted community health workers. Not only does this provide credibility to the researcher, it also creates a level of comfort for the research participant to be actively involved in the interview or discussion during data collection. However, key issues of confidentiality and potential coercion of the research participants are both very important ethical considerations in the design and conduct of community-based public health research (4). These issues must be considered and discussed by the researcher at the design stage and subsequently by the ethics committee during ethics review of the research proposal.

\section{References}

1. Thomas S. Maintaining confidentiality while gaining access to the community, Indian J Med Ethics. 2020 Jan-Mar;5(1) NS:10-1. DOI: 10.20529/IJME.2020.008

2. Geldsetzer P, Vaikath M, De Neve JW, Bossert TJ, Sibandze S, Mkhwanazi M, Bärnighausen T. Distrusting community health workers with confidential health information: a convergent mixed-methods study in Swaziland. Health Policy Plan 2017 Jul 1;32(6):882-9.

3. Grant M, Wilford A, Haskins L, Phakathi S, Mntambo N, Horwood CM. Trust of community health workers influences the acceptance of community-based maternal and child health services. Afr J Prim Health Care Fam Med. 2017 May 29;9(1): 1281.

4. Damianakis T, Woodford M.R. Qualitative research with small connected communities: generating new knowledge while upholding research ethics. Qual Health Res. 2012 May 22; 22(5):708-18.

\title{
Autonomy and risk in health policy and systems research
}

\section{MALU MOHAN}

Keywords: Autonomy, risk, health policy and systems research, informed consent, written consent, waiver of consent, participation in HPSR

\section{Introduction and context}

Health policy and systems research (HPSR), a critical area of public health research, aims to enhance our understanding about how health systems function and how health policies are generated and implemented. HPSR predominantly operates in "real life contexts" of communities or institutions (1). Such contexts significantly reduce the ability of researchers to exert the same level of control over their environment that is possible in biomedical/clinical research. A recent expert consultation led by the World Health Organisation, to explore the knowledge gap relevant to ethical review and practice of HPSR, recommends capacity building for local research ethics committees to deal with its complexities (2). This case presents the ethical dilemma faced by a public health researcher exploring the development of key policies governing the regulation of a specific branch of the health professions.

\section{The case}

The research aimed to analyse the policies which governed the education sector of a particular branch of health professional education in the country. This required interviewing civil servants and other officials from central regulatory agencies. The Institutional Ethics Committee (IEC) of the central institute

\footnotetext{
Author: Malu Mohan (dr.malumohan@gmail.com), Research Coordinator Project on Decentralisation and Health: Lessons from the Kerala Experience, Kerala Institute of Local Administration, Thrissur, Kerala, INDIA.

To cite: Mohan M. Autonomy and risk in health policy and systems research. Indian J Med Ethics. 2020 Jan-Mar;5(1) NS:13-4 DOI: 10.20529/IJME.2020.010.

CIndian Journal of Medical Ethics 2020.
}

where this research was conceived follows the Indian Council for Medical Research guidelines for ethical review of research proposals. These guidelines are predominantly governed by a biomedical/clinical research paradigm. The guidelines mandate that researchers obtain written informed consent from all prospective participants or their legally acceptable/authorised representatives, with few specific circumstances where a waiver could be sought. The researcher anticipated that most of the policy actors would not be comfortable signing a written informed consent document. However, the IEC directed that all participants had to give written informed consent prior to participation.

After the research proposal was cleared by the IEC, a key actor in the policy process was introduced to the researcher. This was a central government officer who had served for a long period in one of the central regulatory agencies responsible for major policy decisions relevant to the research. He told the researcher that he disagreed with many of these policy decisions but did not oppose them because he was just a cog in the wheel and had limited ability to initiate pressures or resist change.

The officer expressed willingness to participate in the study and share his own notes and personal research. He also consented to audio recording of the interviews on condition that he would operate the recorder himself, so that he could pause the recording in the midst of a conversation when he did not want to place the divulging of a specific piece of information on record, and continue when he wished to be on record. However, when the researcher sought his written informed consent to participate, the officer categorically stated that although he was willing to cooperate with the research, there was no question of signing any document.

\section{The dilemma}

The retired official could be a key informant to the research, 
since he was an important policy actor. He had expressed his interest in participating, offered to share his research and given his consent (conditional) to audio recording. His refusal was only to signing a document which, if revealed, could affect his reputation in government circles and lead to hostility from his former colleagues.

The proposed HPSR ethics framework requires researchers to consider the potential institutional reputational risks to participants and warn potential participants of this risk (2). Many retired officials get work assignments and deputations from the government. In this case, if the official's participation in the research project became known, he could face hostility and stigma in official circles, and lose job opportunities.

In this case, the researcher's dilemma was twofold:

- If she decided to engage with the participant without insisting on written consent, the research would be violating regulations.

- If she decided to forego his participation, she would miss gathering important insights on policy issues in her research subject.

\section{Questions raised by the case}

1. Could the researcher have conducted ethical research without doing the project injustice?

2. What alternative measures could have been suggested by the IEC in this case?

3. Does the requirement of signed informed consent uphold participants' autonomy?

4. Should the concept of "risk" be redefined in the context of public health research?

\section{References}

1. Alliance for Health Systems and Policy Research. Briefing Note 1. What is health policy and systems research and why does it matter? Geneva: Alliance HPSR, WHO; 2007 Jun[cited 2019 Dec 12]. Available from: https://www.gov.uk/dfid-research-outputs/what-is-health-policy-andsystems-research-and-why-does-it-matter

2. Luyckx VA, Biller-Andorno N, Saxena A, Tran NT. Health policy and systems research:towards a better understanding and review of ethical issues. BMJ Glob Health. 2017;2:e000314.

\section{Between participation and signature: a response to "Autonomy and risk in HPSR studies"}

\section{RAKHI GHOSHAL}

Keywords: Autonomy, risk, health policy and systems research, informed consent, written consent, waiver of consent, participation in HSPR

\section{A background}

Health Policy and Systems Research (HPSR) is defined as the "production of new knowledge to improve how societies organise themselves to achieve health goals" (1: $p$ 4); the focus of HPSR studies is on generating, using and disseminating research to strengthen health systems, particularly in lowand middle-income countries. There has been an increasing focus on defining HPSR clearly and on its ethical components and challenges, especially as this domain, is fundamentally different from biomedical /clinical research. One of the imperatives of HPSR is the "co-production of knowledge" (1: $p$ 4) by the researcher, the communities involved, and healthcare providers; and this calls for shared responsibility

Author: Rakhi Ghoshal (rakhi.ghoshal@gmail.com), CARE India, Patna, Bihar 800 013. INDIA.

To cite: Ghoshal R. Between participation and signature: a response to "Autonomy and risk in HPSR studies". Indian J Med Ethics. 2020 Jan-Mar; 5(1) NS:14-6 DOI: 10.20529/IJME.2020.011.

Peer Reviewers: Rakhal Gaitonde and an anonymous reviewer.

CIndian Journal of Medical Ethics 2020 and ownership, which is not an essential aspect of biomedical research

Our understanding of research ethics is challenged when the standards of biomedical research are applied to HPSR studies; especially when obtaining consent and protecting confidentiality become difficult. These aspects are exemplified in this case study (2), where the research participant, a senior level policy maker with the government, refused to give written consent even as he was willing to participate in the study. He did not feel confident about his identity remaining confidential once he had signed the informed consent sheet. His concern stemmed from the need to avoid a possible whistleblower image which could jeopardise his association with the government.

While what the senior policy maker had to share would be valuable for the study, the information could not be used by the researcher without a waiver of written informed consent from the IEC. The key issue here is whether informed consent is equal to written informed consent. The 2019 WHO Guidelines (1) say: "Researchers and RECs must proceed on the presumption that the informed consent of policy-makers, decision-makers and health providers in HPSR studies is required". However, with respect to obtaining the option of a consent waiver, the guidelines $(1: p$ 9) further clarify that:

"While the requirement for informed consent of patients in 